\title{
MUJERES INDIGENAS EN TIEMIPOS DE PANDEMIA EN LA AMAZONIA ECUATORIANA
}

INDIGENOUS WOMEN IN PANDEMIC TIMES IN THE ECUADORIAN AMAZON

\section{MULHERES INDÍGENAS EM TEMPOS PANDÊMICOS NA AMAZÔNIA EQUATORIANA}

Facultad Latinoamericana de Ciencias Sociales (FLACSO) ivallejo@flacso.edu.ec Ecuador

Lisset Coba

Doctora en Ciencias Sociales Facultad Latinoamericana de Ciencias Sociales (FLACSO) lcoba@flacso.edu.ec Ecuador

Marisol Rodriguez

Candidata a doctora y Master en Antropología Social Facultad Latinoamericana de Ciencias Sociales (FLACSO) marintirp@yahoo.com Ecuador

\section{Renata Mantilla}

Candidata a Master en Estudios Socioambientales Facultad Latinoamericana de Ciencias Sociales (FLACSO) renatamantilla13@gmail.com Ecuador

Natalia Valdivieso Candidata a doctora y Master en Antropología Social Universidad de Manchester, UK nvaldiviesok@hotmail.com

Ecuador

Celeste Torres

Master en Antropología Visual Facultad Latinoamericana de Ciencias Sociales (FLACSO) cinedisidente@gmail.com

Chile 


\section{Resumen}

La necropolítica gubernamental del Estado ecuatoriano coadyuva al padecimiento y muerte en la Amazonía, como parte de un ejercicio etnocida y ecocida. En medio de la pandemia, el Estado vulnera derechos y deja morir, asumiendo la desechabilidad de territorios y pueblos indígenas al no garantizarles atención en salud, y negarles medidas de reparación integral ante la contaminación petrolera y otros desastres ambientales. El artículo, desde las voces de mujeres indígenas, profundiza en las afectaciones que experimentan sus comunidades, la inacción del Estado, y las estrategias que accionan desde sus organizaciones para exigir justicia y atención. Los conocimientos ancestrales y las prácticas curativas han sido la estrategia para preservar la vida.

Palabras clave: necropolítica, mujeres indígenas, coronavirus, Amazonía.

\section{Abstract}

The government necropolitics of the Ecuadorian State contributes to suffering and death in the Amazon, as part of an ethnocidal and ecocidal exercise. In the midst of the pandemic, the State violates rights and lets people die, assuming the disposability of indigenous peoples and territories by not guaranteeing them health care, and denying them comprehensive reparation measures in the face of oil pollution and other environmental disasters. The article, from the voices of indigenous women, delves into the effects that their communities experience, the inaction of the State, and the strategies that their organizations act to demand justice and attention. Ancestral knowledge and healing practices have been the strategy to preserve life

Keywords: necropolitics, indigenous women, coronavirus, Amazon

\section{Resumo}

A necropolítica governamental do Estado equatoriano contribui para o sofrimento e a morte na Amazônia, como parte de um exercício etnocida e ecocida. Em meio à pandemia, o Estado viola direitos e deixa pessoas morrerem, assumindo a disposição dos povos e territórios indígenas, não garantindo saúde, e negando-lhes medidas integrais de reparação em face da poluição por óleo e outros desastres ambientais.

Palavras-chave: necropolítica, mulheres indígenas, coronavírus, Amazônia. 


\section{El coronavirus, una nueva pandemia en la Amazonía}

\begin{abstract}
"Antes waorani morían por shamanismo, mordedura de culebra, caída de árbol o mal parto, estas eran las enfermedades que conocían antes del contacto. Desde la llegada del hombre blanco, en el primer contacto con los evangélicos, llegaron la polio, el sarampión, hepatitis, fiebre amarilla y el dengue. Murieron bastantes waorani, allá por los años 40 y 60 . Antes waorani vivian sin enfermedades, vivian de la selva. Ahora el Covid, también llega con personas de afuera de las comunidades".
\end{abstract}

Nemonte Nenquimo, lideresa waorani, 2020.

\section{iversos estudios muestran cómo}

las epidemias han formado

parte de una historia de colonización y expoliación en la cuenca Amazónica, desde la frenética búsqueda de El Dorado y el País de la Canela en el siglo XVI1 (Cabodevilla 2013, Chambouleyron

\footnotetext{
${ }^{1}$ Chambouleyron (Et al. 2011) señala los reportes de los siglos XVII y XVIII en que misioneros jesuitas narran sobre la "plaga de la viruela. La despoblación representó una "gran crisis para el sistema de producción, agotando la fuerza laboral", la solución fue la captura de esclavos y el reparto de los indios, la creación de rutas para el tráfico de esclavos negros. Santos Granero $(1987,1996)$, también en el siglo XVIII, expone el declive demográfico de los Amuesha en el Perú, la concentración de poblaciones por las misiones franciscanas, aportaron a la propagación de la viruela. Aquellos pobladores que huían eran perseguidos y castigados. Gómez $(1995,1998)$ resalta el etnocidio de 90 tribus, a fines del siglo XIX e inicios del XX como resultado de distintos sistemas de coerción de misioneros, hacendados, de trabajo obligatorio para la extracción de quina, caucho, oro, pieles, petróleo. En la misma época, en Ecuador, Cabodevilla (2013) registra la disminución de las poblaciones por fiebre amarilla.
}

Et al. 2011, Gómez 1998, Santos Granero 1987- 1996), el Covid-19 en el siglo XXI, no es una excepción. En la Amazonía, el coronavirus se inserta en una región presionada por industrias extractivas petroleras, mineras, el agronegocio y la extracción forestal (Alencar et al 2020, López-Feldman 2020, Malheiro et al. 2020, Verdum 2012, Villavicencio et al. 2020)2. En Ecuador, este escenario se agrava por graves desastres ambientales: uno de los derrames de crudo más graves de la historia y el desborde de importantes ríos que han arrasado comunidades enteras.

En los distintos países de la cuenca amazónica, las tasas de letalidad son elevadas al compararse sus cifras de contagio y fallecimiento, con los registros nacionales (Fellow M, et al 2020) ${ }^{3}$. En la Amazonía ecuatoriana, para fines de agosto se reportaban 10.198 casos de contagio, de un total de 101.593 personas contagiadas por coronavirus en Ecuador (COE

\footnotetext{
${ }^{2}$ Como enfermedad infecciosa emergente de origen zoonótico, transmitida de animales a humanos, nos revela que la relación entre los seres humanos con la naturaleza ha cruzado el límite de la sustentabilidad (De Castro Et al. 2020), al incrementarse las intervenciones antrópicas como la deforestación, la degradación ambiental y la comercialización de vida silvestre.

${ }^{3}$ En la cuenca Amazónica se registran 221 pueblos indígenas afectados, 44.881 casos de contagio por COVID-19 y 1.442 fallecimientos, con situaciones críticas en Brasil, Perú, Colombia y Bolivia. En la Amazonía de Brasil existen 19.134 casos confirmados de contagio en pueblos indígenas y 579 fallecimientos; la Amazonía peruana tiene 11.566 casos confirmados y 387 fallecimientos en pueblos indígenas; Colombia tiene 9.000 casos de contagio y 286 fallecimientos, seguida de Bolivia con 2.564 casos y 104 fallecimientos (REPAMCOICA 19-08-2020).
} 
Nacional-26/08/2020). De estos, 2.321 casos positivos se encuentran en pueblos indígenas, con 82 fallecimientos (CONFENIAE, 20-08-2020). Las provincias con mayor número de contagios son Pastaza (620 casos), Orellana (509), Napo (384), Sucumbíos (273) y Zamora Chinchipe (95) (Ver Cuadro 1).

\section{Gráfica 1. Registro COVID-19 por Nacionalidades amazónicas}

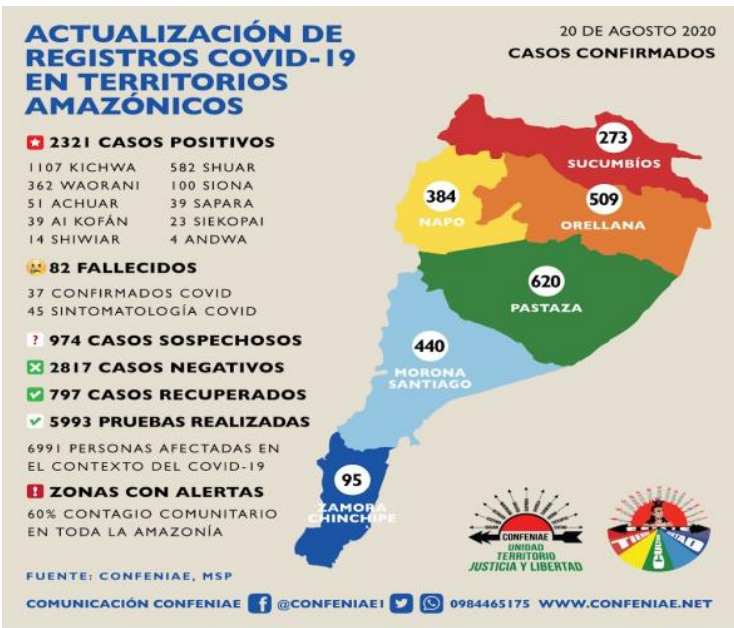

Fuente: CONFENIAE

Los primeros síntomas se registraron en abril en las nacionalidades siekopai en la provincia de Sucumbíos y waorani en Orellana; para mayo de 2020, 47 casos fueron reportados ${ }^{4}$. Junio y julio fueron los meses de mayor contagio, con

\footnotetext{
${ }^{4}$ El Comercio, 01/05/2020, CONAIE presenta balance sobre impacto del covid-19 en territorios indígenas. https://www.elcomercio.com/actualidad/conaiebalance-impacto-covid19-indigenas.html.

5 En grupos de parentesco siona, siekopai, sapara y andwa todavía con pocos casos, cualquier aumento podría ser devastador en términos demográficos. El
}

tendencia a incrementarse en los pueblos kichwa, shuar y waorani (Monitoreo del COVID-19 (CONFENIAE 2020)5. En estos contextos de catástrofes ambientales, profundización del extractivismo y desatención del Estado y por tanto, profunda vulnerabilidad, las mujeres amazónicas han debido lidiar con la necropolítica de un Estado que los deja morir y les considera desechables (Mbembe 2019). La contaminación de los ríos, la falta de agua limpia, así como el tortuoso camino del acceso a la justicia que han planteado las organizaciones sociales son el contexto en que las mujeres han desarrollado distintas estrategias que van desde las acciones políticas hasta el desarrollo de saberes curativos.

En este artículo nos preguntamos: ¿Cómo perciben las mujeres indígenas amazónicas la afectación de esta pandemia en sus comunidades? ¿Cómo explican los flujos de contagio en relación con las presiones existentes sobre sus territorios? ¿Cuál es el accionar del Estado respecto del acceso a servicios de atención en salud? Finalmente, ¿Qué acciones han legales y qué estrategias de

efecto puede ser pernicioso en la nacionalidad waorani, con un poco más de cincuenta años de reciente contacto con la sociedad nacional; más aún si llegaran a contagiarse pueblos indígenas aislados como Tagaeri y Taromenane en el Parque Nacional y Reserva de Biósfera Yasuní. 
contención y cuidados han asumido frente a la pandemia?

A pesar de que la Amazonía ha constituido el lugar de obtención de divisas del país debido a la explotación petrolera, desde los años sesenta, los pueblos indígenas y las mujeres en especial, han sido afectadas por la distribución económica y ecológica desigual de esta actividad. La expansión de la pandemia, junto a la recurrente exposición a contaminantes han fragilizado la vida y han convertido a la Amazonía en zona de sacrificio $^{6}$. Pese a la heterogeneidad de los casos, las jerarquías de género preexistentes se han visto agudizadas debido a todas las labores de cuidado y sanitización, más aún en los lugares de catástrofe ambiental. Desde este contexto, planteamos en un primer apartado una discusión que aborda la relación entre racismo ambiental, necropolítica y género. En un segundo los flujos de contagio, primeros síntomas y vulnerabilidades; en un tercero dejar morir y autogobierno; en un cuarto, ecocidio: derrame de crudo e inundaciones en medio de la pandemia. En un quinto, accionando derechos y el tortuoso camino del acceso a la justicia; y finalmente, las mujeres y el

\footnotetext{
${ }^{6}$ Svampa y Viale (2014) caracterizan a las zonas de sacrificio como aquellas en que altos niveles de contaminación y daños ambientales producidos antes por el desarrollismo y actualmente por el neoliberalismo, afectan a poblaciones y entornos.
}

autogobierno desde los saberes curativos, para luego cerrar con las conclusiones.

Esta investigación se basa en entrevistas in situ, otras virtuales, archivos de audio de webinares en que han participado lideresas amazónicas, revisión de fuentes documentales de la Confederación de Nacionalidades Indígenas de la Amazonía Ecuatoriana (CONFENIAE) y otras organizaciones, así como revisión de artículos de prensa. ${ }^{7}$

\section{Racismo ambiental, necropolítica y género: breve discusión teórica}

El racismo ambiental es parte de un racismo estructural que implica la continuidad histórica colonial perpetuadora de inequidades en la salud sobre las personas racializadas provocando sufrimiento desproporcionado, morbilidad y mortalidad (Gee y Chandra, 2011; Tiffany, 2020; Powell, 2008; Pulido, 2016; Zinzi, et al., 2017). En el contexto de la pandemia, la segregación residencial, territorial, ocupacional y las desigualdades, el acceso a información afectan a la

\footnotetext{
${ }^{7}$ Parte de las entrevistas fueron realizadas en el marco de la Docuserie "Sacha Samay: aliento de vida frente a la pandemia" elaborado por FLACSO Ecuador con auspicio de Fundación Rosa Luxembrugo; se revisaron audios de webinares de la Red Waponi (solidaridad con la nacionalidad waorani).
} 
exposición a riesgos como agentes infecciosos. Además, al acceso a otras condiciones como justicia, políticas de salud, servicios y oportunidades que normalizan y legitiman los privilegios de unas poblaciones sobre otras, inciden en las capacidades para practicar la distancia social $^{8}$ (De Castro et al., 2020; De Souza Santos, 2020; Iglesias-Osores, et al., 2020; Malheiro et al., 2020, Pulido, 2016; Tiffany, 2020; Williams y Collins, 2001 en Gee y Chandra, 2011).

El racismo ambiental está condicionado por los principios biopolíticos y necropolíticos que como sostiene Estévez (2018) son complementarios. Siguiendo a Foucault (2007), el biopoder usa tecnologías de administración de la población: medicina, estadística, control natal, política pública, etc. Sin embargo, para Mbembe (1999), en el tercer mundo, un estado sistemático de emergencia revela a la necropolítica o dispositivo de muerte como condición de desechabilidad, en que las normas se vuelven más importantes que el sistema judicial mismo. En contextos de pandemia, el racismo estructural es necropolítica que desencadena una serie de vulneraciones previas, según Menezes et al. (2020), la pedagogía del miedo y la

\footnotetext{
${ }^{8}$ Para De Souza Santos (2020) la disparidad en salud reproductiva en Brasil respecto del Covid-19, en mujeres embarazadas o en situación de postparto y con una morbilidad similar, es desigual respecto de mujeres
}

ausencia de medidas de protección podrían generar genocidio 9 . Si tomamos el caso de las mujeres amazónicas, raza, etnicidad y género se enlazan minando las oportunidades de diagnósticos, monitoreo, y tratamientos efectivos y específicos, exacerbando las inequidades.

La pandemia es solo un síntoma de un modelo de desarrollo destructivo del planeta que demuestra que no hay ningún desastre estrictamente natural (Vallejo y Álvarez, 2020). En la Amazonía, la necropolítica, a la par, administra la destrucción de hábitat, el poder de dar muerte se expresa en tecnologías de explotación y destrucción de cuerpos; así como en "dispositivos legales, administrativos que operan y sistematizan sus efectos" (Estévez, 2018:10). Existen poblaciones que se las deja morir, al ser omitidas como objetos de política pública; así el capitalismo necropolítico, puede conducir la vida (incluyendo a los seres no humanos) hacia la precariedad, o incluso la extinción, formas organizacionales de acumulación que involucran “desposesión, muerte, suicidio, destrucción de hábitats y la administración general de la violencia" (Estévez, 2018:30).

hospitalizadas racializadas quienes poseen menor acceso a cuidados intensivos y mayor probabilidad de muerte.

9 Oliveira et al. (2020), señala la posibilidad de dispersión del nuevo coronavirus en comunidades indígenas que amenaza incluso para los grupos étnicos más aislados. 
Una forma necropolítica como "el ecocidio o suicidio ambiental [...], no se reduce a un delito ambiental común ni se restringen a un daño a la propiedad [...], implica la noción de guerra total porque no solo afecta a los combatientes, traslada sus efectos a civiles y al conjunto de las condiciones de vida (Neira Et, al. 2019: 1). Ecofeministas como Herrero (2016) y Monasterio y Weingärtner (2010), sostienen que el mundo se enfrenta a una guerra contra la vida; no obstante, en la larga historia del capitalismo es fundamental reconocer todas aquellas formas creativas que reproducen la vida aún en las zonas de sacrificio como la Amazonía.

\section{Flujos de contagio y primeros síntomas. Vulnerabilidades.}

Desde la perspectiva de las mujeres indígenas amazónicas, los contagios están relacionados con las dinámicas extractivas petroleras, forestales y mineras, intensificadas durante la pandemia. En comunidades del territorio wao en las provincias de Napo y Orellana, personal de empresas petroleras en varios de los bloques que operan en el Yasuní mantuvieron la rotación de cuadrillas de trabajadores. Algo

10 Entrevista a Rosa Aranda. Presidenta de la comunidad Pihuiri y de la Asociación Sumak Kawsai. Territorio de Moretecocha, Pastaza. similar ocurrió en la zona del bloque 10, en Pastaza. A pesar de la cuarentena y la restricción a la movilidad, las operaciones petroleras no pararon como relata una lideresa: "A fines de febrero entramos a cuarentena. Supuestamente nadie tenía que ingresar a las comunidades. Nosotros estamos al frente del pozo petrolero y la empresa petrolera operó normalmente". ${ }^{10}$

Mujeres kichwa y waorani también atribuyen los contagios al extractivismo forestal ilegal, debido a comerciantes de balsa que ingresaron a las comunidades por vía fluvial o terrestre, en acuerdo con dirigentes o miembros de las mismas para extraer la madera. Los "balseros" como les denominan, provienen de la costa ecuatoriana, de Guayaquil, ciudad que tuvo el mayor nivel de contagios y fallecimientos entre marzo y abril. Al respecto del ingreso de balseros, dicen lo siguiente:

"El personal de empresas balseras en su mayoría son de Guayaquil. Ahí había brotado el Covid, y es así como llegó el virus a las comunidades. De eso estamos seguros. Ellos llegan a las comunidades, o averiguan quién es el presidente de tal comunidad, se contactan, ahí ven qué familias quieren vender. Así hacen contacto con la comunidad y cuando entran a sacar la balsa colocan carpas, maquinarias y están trabajando por días. Muchos por necesidad de mano de obra trabajan con ellos. 
Luego regresan a la casa y luego de quince días recién se darán cuenta del brote del virus. Los balseros entran sin mascarillas, no usan trajes de bioseguridad. Muchas personas estamos expuestas porque en las comunidades no usamos mascarilla, guantes, ni alcohol. Pusimos una queja al UPC de Arajuno con el COE cantonal, pero no hicieron caso al principio. A fines de mayo se fueron, pero ya quedaron infectados mucha gente". ${ }^{11}$

Las dinámicas de movilidad de poblaciones indígenas entre comunidades, sectores rurales y zonas urbanas inciden también en los contagios, cuando por necesidad las familias salen a comprar alimentos procesados e insumos en ciudades como Puyo, Tena, Lago Agrio y Coca, y cabeceras cantonales.

En la Nacionalidad waorani, las comunidades de Miwaguno, Yewepare y Batoboro en Orellana y Pastaza, fueron las primeras en presentar síntomas. El contagio se produjo debido a la cercanía con carreteras, pistas de aterrizaje, extracción de madera ilícita y actividades petroleras, que no cesaron, en medio del distanciamiento social establecido por el gobierno. También la gente continuó con eventos culturales y festividades, a pesar de la pandemia, diseminándose el virus. En comunidades como Dicaro, Teweno, Toñampare y Kenaweno en Pastaza

11 Entrevista a Rosa Aranda. Presidenta de la comunidad Pihuiri y de la Asociación Sumak Kawsai. Territorio de Moretecocha, Pastaza adultos y niños se enfermaron. En zonas más alejadas donde el acceso es fluvial o aéreo, estudiantes que retornaron a sus comunidades, al paralizarse las clases presenciales en establecimientos educativos en las ciudades, resultaron portadores del virus.

Las mujeres indígenas de la Amazonía narran cómo la pandemia golpeó fuertemente a la mayoría de familias en las comunidades. Ellas se sorprendieron por la gran cantidad de casos y la velocidad del contagio.

“[...] declararon quedarse en casa, la gente se asustó y se fueron a sus fincas. No estábamos preparados. Cuando la enfermedad llegó a las comunidades, no tenían dinero, no había transporte, estaba cerrada la vía. Se contagiaba uno, después otro al siguiente día y otro al siguiente. Era como si el barbasco hubiera caído en el río, cayendo uno y otro pez. Así se enfermaban toditos por igual. En la comunidad de repente todo el pueblo se enfermó". ${ }^{12}$

Muchas mujeres testimonian sus condiciones de salud debilitadas por exposición a contaminantes, lo que ha enfermado sus cuerpos. Este es el caso de las comunidades de Villano en el bloque 10 (operado más de veinte años por AGIP); en esa

\footnotetext{
12 Entrevista Zuritiak Naichamp. Comunidad shuar de Warintz, Morona Santiago.
} 
zona hay muchas personas con hepatitis, problemas respiratorios y afecciones pulmonares. En las comunidades waorani, también las mujeres hacen mención a enfermedades prevalentes como anemia, dengue, sumadas a desnutrición que crearon condiciones de vulnerabilidad, lo que propició que el Covid-19 afecte con severidad.

Medidas como el distanciamiento social que recomienda el Servicio Nacional de Gestión de Riesgos y Emergencias (COE) y funcionarios del sector de salud son difíciles de cumplir en las comunidades indígenas en donde se comparte chicha, guayusa, y se efectúan trabajos colectivos (mingas) y se usa barbasco para pescar en los ríos de forma conjunta. Incluso, en medio de la pandemia, las familias se visitan para asistirse lo que acelera el ritmo de la propagación; lo mismo ocurre con los velatorios.

Las mujeres relatan que al enfermarse les faltó fuerza para cultivar. Cuando los hombres se enfermaron, ellas asumieron la pesca, pues la cacería se vio limitada. La principal preocupación fue que al enfermarse ellas, los $\operatorname{agroecosistemas}^{13}$ se remontarían; no habría quién trabaje en los cultivos y que la economía familiar se afecte.

13 Las chakras (en las familias kichwa), kewenkore (waorani), aja (shuar).
Cuando aumentaron los contagios, las que no se enfermaron o no tenían síntomas asistían a otras, apoyándoles en los cuidados. Iban a sus chakras a recoger los cultivos para ayudarles a preparar comida; por ello se recargaron de trabajo. A diferencia de las dinámicas urbanas donde cada quien enfrenta la pandemia, en la Amazonía el tejido social se activó y sostuvo con las mujeres.

\begin{abstract}
"Las actividades de las mujeres aumentaron más que las de los hombres. Cuando los hombres se enfermaban ellas les atendían, pero cuando las mamitas se enfermaban el esposo ni siquiera les atendía. Una mujer enferma tenía que irse a su chakrita y después llegaban ya tarde y se empeoraban de su enfermedad. Yo les decía a ellos (a los esposos) "si ella está enferma, tienes que ayudarla". En la cultura shuar, la mujer hace más trabajo que el hombre. Hace la chicha, atiende al esposo, cuida a los hijos. ¿Y quién cuida de ellas?"14
\end{abstract}

En épocas previas, las familias de pueblos amazónicos frente a otras epidemias tenían estrategias como adentrarse en la selva, acudir a tambos para alejarse de los centros poblados y evitar contagios (Vallejo y Álvarez, 2020), pero cada vez hay menos territorios indígenas sin industrias extractivas. Actualmente se suma, la necesidad de

14 Entrevista a Suritiak Naichamp. Comunidad shuar de Warintz, Morona Santiago. 
intensificar la limpieza, la desinfección de las casas y por los cuidados requeridos en la atención cotidiana de los enfermos.

\section{Dejar morir y autogobierno}

En la Amazonía, los subcentros de salud localizados en las cabeceras de las juntas parroquiales no cuentan con equipamiento, ni insumos necesarios para diagnosticar y atender los casos de contagio del covid-19; y el acceso a los centros hospitalarios ubicados en las ciudades amazónicas es limitado para las mujeres y sus grupos familiares por las distancias geográficas existentes. Las unidades de cuidados intensivos de los hospitales de Lago Agrio, Coca y Puyo han colapsado. Como enuncia una lideresa kichwa de Pastaza "Mucha gente no tiene posibilidad de salir a un hospital. No tenemos acceso. Nosotros a nuestras comunidades hay que ir en canoa. Muy pocas están a lado de la vía". ${ }^{15}$

Dada la estratificación del sistema de salud pública y por ende su limitada cobertura en la Amazonía, la capacidad de prestar atención ante la pandemia ha sido reducida (Sojo, 2020). En la región hay condiciones deficitarias de atención en

15 Entrevista a Rosa Aranda. Presidenta de la comunidad Pihuiri y de la Asociación Sumak Kawsai. Territorio de Moretecocha, Pastaza. salud, una limitada infraestructura sanitaria y débil capacidad de vigilancia epidemiológica, a lo que se agrega la desidia estatal en generar estrategias hacia poblaciones indígenas (Meneses, et al., 2020). La diseminación del coronavirus entre los pueblos amazónicos puede leerse como necropolítica, en los términos de Mbembe (2019), aquella potestad que se atribuyen élites económicas y políticas articuladas al Estado, de exponer a la gente a la muerte, lo que se gesta en la Amazonía sobre una historia de larga data, de exclusión y exterminio (Conde, 2020).

El Ministerio de Salud Pública (MSP) no proporcionó información a las comunidades, ni campañas de comunicación culturalmente adecuadas para la realidad amazónica. Cuando comenzaron a evidenciarse síntomas entre las familias, muchas lideresas y dirigentes realizaron gestiones ante los distritos de salud cantonales, sin obtener asistencia de brigadas médicas. En varios casos, las brigadas médicas del MSP llegaban un mes después cuando ya habían fallecido personas, o cuando ya los síntomas y padecimiento grave había pasado.

Conforme relata una mujer shuar, las comunidades han sido "invisibles" 
para el Estado, para funcionarios del MSP

y para los gobiernos seccionales.

Aquí el Ministerio de Salud Pública (en Morona Santiago) no dio una buena información para alertarnos. No he visto hasta el momento que haya habido pruebas rápidas. Solo cuando iba la gente a Macas había un control donde tomaban la fiebre. Los centros de salud pasaban cerrados. No hubo funcionarios que hayan venido a hacer pruebas. Nada. No hemos tenido apoyo. No hubo apoyo de la red pública, ni de los gobiernos seccionales del cantón. El pueblo por sí solo tenía que sobrevivir. Esa ha sido la realidad. Hemos sido invisibles para ellos. ${ }^{16}$

El Estado no ha presentado atención ante los casos de contagio. Menciona una lideresa waorani "Nadie nos quiere salvar, solo nosotros mismo nos salvamos". ${ }^{17}$ Cuando jóvenes contagiados han acudido a los hospitales, han recibido una limitada atención, mientras los subcentros de salud no tienen medicamentos, ni respiradores.

Una lideresa kichwa de la Asociación Sumak Kawsay relata incluso que el personal médico tenía temor de trasladarse al interior de la Amazonía:

"Fue una burocracia completa para coordinar una brigada médica. CONFENIAE consiguió pruebas PCR por autogestión y 20 pruebas eran para nuestra zona (Villano). Los

16 Entrevista a Suritiak Naichamp. Comunidad shuar de Warintz, Morona Santiago.

17 Entrevista a Nemonte Nenquimo. Presidenta de CONCONAWEP. Comunidad de Nemonpare. médicos tenían miedo de ir a nuestras comunidades. Yo me tuve que poner brava. Se excusaban primero diciendo que no tenían pruebas PCR, que ya se habían terminado en la cabecera del distrito. Ahí yo hablé con un dirigente de la CONFENIAE y me dijo, nosotros sí tenemos, pero necesitamos conseguir personal médico. Ahí yo fui a pedirles a los médicos del distrito de Arajuno, pero no querían ir. Tenían miedo. Después, recién después de un mes fueron, pero ya habían pasado los síntomas". ${ }^{18}$

Esta desidia en atender a comunidades indígenas, revela discriminación étnica, un tratamiento como si se tratara de ciudadanos de segunda categoría. La necropolítica envuelve al Estado y también a empresas petroleras que operan bloques en la Amazonía. Algunas, como PlusPetrol, que actualmente opera el bloque 10 en Villano, en Pastaza proporcionan equipamiento a subcentros de salud en su área de influencia y bonificaciones a promotores de salud comunitaria, pero en tiempos del Covid19, se dimensionó aún más el discrimen que sufren comunidades que se resisten y oponen al extractivismo, al negárseles atención médica, y acceso a insumos y fármacos.

Ante la inacción del MSP y COE, organizaciones indígenas como la CONFENIAE y sus filiales han activado

18 Entrevista a Rosa Aranda. Presidenta de la comunidad Pihuiri y de la Asociación Sumak Kawsai. Territorio de Moretecpcha, Pastaza. 
alianzas con $\mathrm{ONG}^{19}$ y universidades ${ }^{20}$ para implementar estrategias comunicacionales de información sobre la pandemia, elaborar protocolos, cartillas preventivas en varias lenguas indígenas, gestionar la asistencia de brigadas y la implementación de pruebas rápidas y de PCR.

\section{Fotografia 1: Toma de Pruebas PRC en Teweno, comunidad waorani}

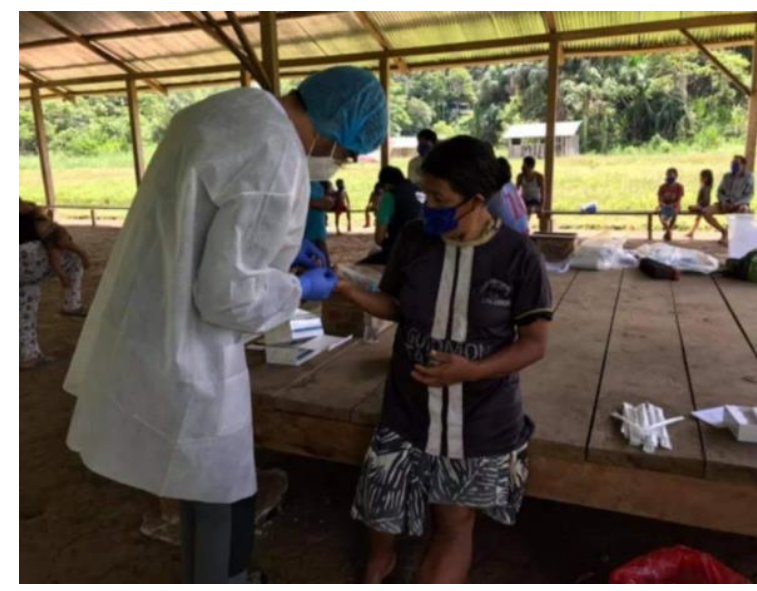

Fuente: CONCONAWEP, 2020.

La nacionalidad achuar asumió como medida de prevención, mantener cerradas las pistas aéreas para evitar ingresos a sus comunidades; algo similar efectuó la nacionalidad waorani. Las organizaciones woarani de Pastaza junto con la NAWE a nivel territorial y la Asociación de Mujeres Waorani del Ecuador (AMWAE) desde mayo trabajaron cojuntamente para poner en marcha

19 Alianza Ceibo, Fundación Labaka, Pachamama, Amazon Frontlines, Aldea, Acción Ecológica.

${ }^{20}$ Universidad de Las Américas -UDLA-, Universidad San Francisco de Quito -USFQ-, Universidad Andina Simón Bolívar -UASB-. la elaboración de un protocolo de seguridad y salud para mitigar los contagios dentro de las comunidades $^{21}$. Dentro del protocolo se gestionó la toma de pruebas PCR, la entrega de kits de salud (mascarillas, medicina, gel y alcohol), la entrega de alimentos y víveres a las comunidades.

\section{Fotografía 2. Nemonte Nenkimo (CONCONAWEP) entregando kits en Teweno}

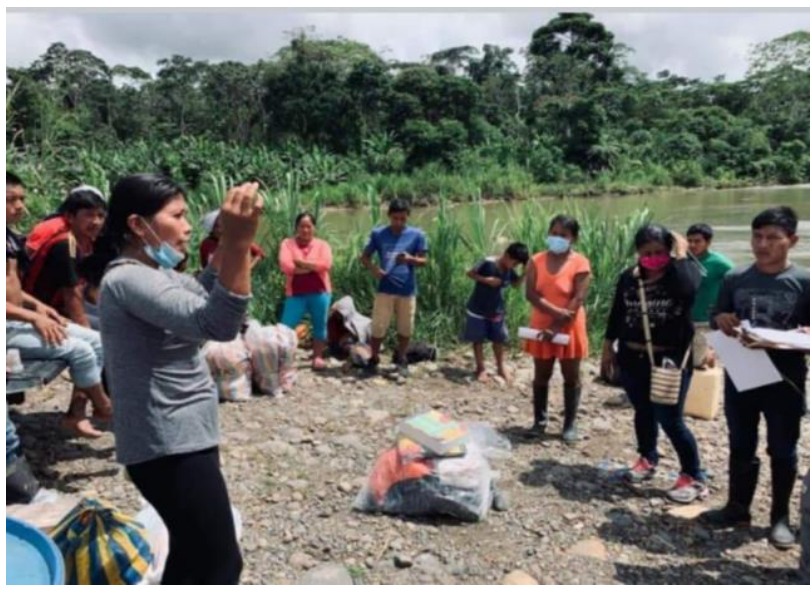

Fuente: CONCONAWEP

Una lideresa shuar comenta las acciones que hicieron desde su organización:

"Comunicamos a nuestras bases diciendo que en los territorios de la FENASH se prohíba estrictamente la entrada, de quienes no sean afines a las familias y comunidades. Esto bajaron a las bases. Desde allí se hizo vocería por medios de comunicación y por internet prohibimos salidas y entradas de

\footnotetext{
${ }^{21}$ Iniciativa llevada a cabo con apoyo del equipo legal de Amazon Frontlines y Alianza Ceibo.
} 
personas particulares. Si alguien de las familias se quedaba afuera, no podía ingresar a las comunidades para que no haya contagios. Esto hicimos tratando de cuidar a las personas de la tercera edad o a otros delicados. El territorio comunitario se restringió. "Nadie puede entrar y nadie puede salir", dijimos. Se promovieron mingas comunitarias para continuar con la vida cotidiana. Estar encerrados conllevaba a desesperación, se trabajaron chakras... cultivos". ${ }^{22}$

En la Federación de Nacionalidades Shuar de Pastaza FENASH-P, cuenta la dirigente que inicialmente decidieron comprar medicamentos con fondos comunitarios. Hicieron una lista de lo necesario, pero al no haber transporte para salir a comprar a las ciudades, las ancianas recomendaron recurrir a la medicina propia para contrarrestar la sintomatología. Sin embargo, para muchas comunidades, el Covid-19 se ha desarrollado en condiciones de desastres ambientales extremos como desbordes de ríos, inundaciones, y el derrame de crudo de mayor impacto en las últimas décadas.

\section{Ecocidio: Derrame de crudo e inundaciones en medio de la pandemia}

Pensamos que el petróleo estaba por encima y por dentro el pescado va a estar bueno. Entonces echamos

22 Entrevista a Yadira Sharupi, comunidade del Consuelo (Vía Puyo-Macas). Dirigenta de Relaciones Internacionales FENASH. atarraya y con mi hija cogimos pescado. Ese momento con la contaminación había bastante pescado. Cogimos bastantito y vinimos a la casa y cocinamos, pero era feísimo ese olor. Del hambre nos tocó comer un poco pero el resto botamos. Venimos manchados de petróleo, ahí era bastante petróleo que bajaba. Por la orilla estaba manchado bastante y todo este montecito. Al siguiente día estaba seco, el agua estaba amarilla y el pescado muerto, puro gallinazo estaba ahí [...] Yo vine bañada de petróleo y al tercer día empezó a darme comezón y a picar un poco y ahora tengo estas manchas [...] Ahora todo el pescado está contaminado, ¿de qué vamos a vivir nosotros? $?^{23}$

En plena pandemia, la mañana del 8 de abril, mujeres y hombres kichwa que habitan en comunidades localizadas en las riberas del río Coca despertaron con la novedad de que por el río, su principal fuente de agua y alimentación, bajaban enormes manchas negras y un profundo olor a combustible inundaba el ambiente. Tan solo unas horas después, arrastrada por el fuerte caudal del río Coca, la mancha había seguido su curso hasta el río Napo, adhiriéndose a las orillas y playas, y arrasando con varios cultivos. Se estimaba que el crudo vertido alcanzaría territorios tan lejanos como Perú debido a la magnitud del derrame y la fuerte corriente del Napo.

En la noche del 7 de abril, las tuberías del Oleoducto de Crudos Pesados (OCP) y del

\footnotetext{
${ }^{23}$ Entrevista Bertha Grefa, Comuna San Pablo.Orellana
} 
Sistema de Oleoducto Transecuatoriano (SOTE), que transportan el crudo extraído en la Amazonía, se rompieron tras un deslave en el sector de San Rafael. En febrero de 2020, la cascada del mismo nombre, una de las más grandes del país y localizada a pocos metros del sitio de ruptura de las tuberías, cambió completamente su curso debido al fenómeno de erosión regresiva ${ }^{24}$ y prácticamente desapareció; situación que muestra una cúspide ecocida. De acuerdo con Morán (2020) y otros expertos, el deslave que ocasionó la ruptura y la desaparición de la cascada están conectados. A unos pocos kilómetros de la zona del desastre, aguas arriba, se ubica la represa hidroeléctrica CocaCodo Sinclair, una mega obra construida en el gobierno de Rafael Correa (2007-2017) que capta gran parte del caudal del río Coca, alterando el flujo del agua y el sedimento. Morán (2020) sostiene que, en paisajes intervenidos como este, la erosión remontante es un fenómeno antrópico; por lo tanto, previsible.

Las mujeres kichwa coinciden que no recibieron alertas oportunas ni por parte de las autoridades locales y menos por las empresas operadoras de los oleoductos. Horas después se enteraron del derrame, algunos por noticias

24 Al respecto consultar Morán, Juan (2020) "Desastres paisajísticos, ambientales y sociales en Ecuador: La caída de la Cascada de San Rafael, la erosión remontante y el derrame que le siguió", http://agenciaecologista.info/2020/07/13/cascada-sanrafael/ en redes sociales, otros por alertas emitidas por radio por las organizaciones indígenas locales, y la mayoría simplemente por lo que evidenciaban a través de sus sentidos. Sin embargo, ese tiempo fue suficiente para que los hombres, mujeres y niños, quienes se bañaron en el río en la mañana que siguió al derrame, muestren severas afectaciones como llagas, quemaduras y sarpullido en la piel. Otros manifiestan haber tenido afecciones en el sistema digestivo debido al consumo de agua y peces contaminados.

\section{Fotografía 3. Cuerpos contaminados por el derrame de petróleo, en tiempos de pandemia. Mayo 2020.}

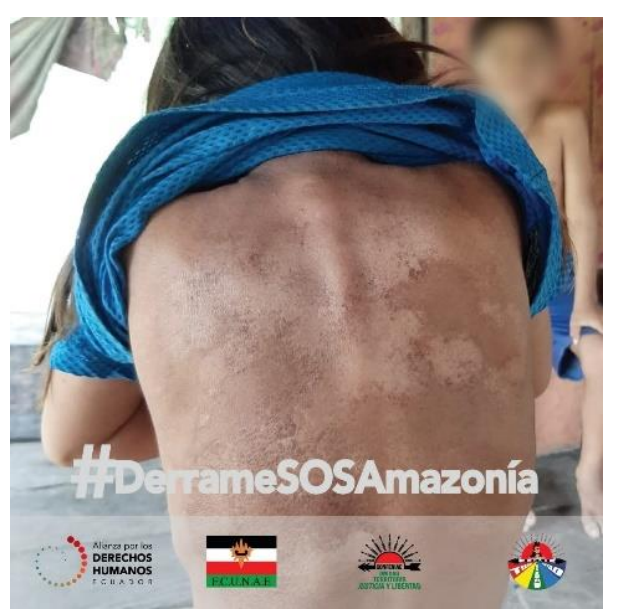

Fuente: Alianza por los Derechos Humanos, CONFENIAE, FCUNAE

Esta no es la primera vez que la población kichwa de las riberas ven sus ríos contaminados con crudo25. Sin embargo,

25 En 2009 casi 14.000 barriles de crudo se derramaron en el mismo río y en 2013 fueron 11.000 los barriles vertidos.

https://www.bbc.com/mundo/noticias/2013/06/13061 0_ciencia_ecuador_derrame_rio_limpieza_ig 
esta vez, aproximadamente 27.000 kichwa de 105 comunidades fueron afectadas. Para las mujeres el agua de los ríos es vital para sus vidas, para la pesca y preparación de alimentos. Allí transcurre parte de la vida recreativa y espiritual de adultos y niños.

Hasta el momento, las empresas operadoras no han emitido un comunicado oficial sobre el número de barriles derramados. Días después del derrame, las empresas operadoras repartieron raciones alimenticias, siendo estas escasas e insuficientes para los miembros de las familias afectadas. No cumplían con los criterios de ingesta proteínica, ni con las formas de alimentación culturalmente adecuadas. Una paca de 4 galones de agua embotellada de 6 litros recibió cada familia ${ }^{26}$. Las mujeres alegan que las entregas no fueron periódicas, ni coordinadas con los dirigentes comunitarios; y destacaron la imposibilidad de acceder a fuentes de agua limpia y alimentos (pesca) sanos. Situación precaria cuando la estrategia difundida por el Estado para contener el Coronavirus ha sido el lavado de manos constante. Expresaba así una mujer kichwa, "En mi familia somos 12 personas ¿Cómo es posible que vivamos con 24 litros de agua durante un mes? Cuando pescábamos en el río nosotros cogíamos hasta

26 La OMS y OPS recomiendan la provisión de 15 litros de agua por persona cada día durante situaciones de emergencia. En este caso, familias de hasta 12 miembros recibían 24 litros para 3 semanas, evidenciando no solo un desconocimiento de las prácticas culturales y falta de concertación con las comunidades indígenas, sino que además este acto
25 peces que nos duraba unos dos días. Ahora, no podemos coger nada. La alimentación que nos dieron, nos duró tres días. ${ }^{27}$

En la época de la pandemia, varias comunidades kichwa y waorani fueron afectadas por inundaciones a partir de la crecida y desborde de ríos Bobonaza, Curaray, Villano, Arajuno y Tiputini. Perdieron sus casas, cultivos y las inundaciones ahuyentaron a los animales, dificultando su acceso a alimento. Con insistencia en gestiones, lograron cierto apoyo de las dependencias cantonales de la Secretaría de Gestión de Riesgos; pero no así en todos los casos.

\section{Fotografía 4: Desborde Río Curaray y afectación Comunidad de Toñampare}

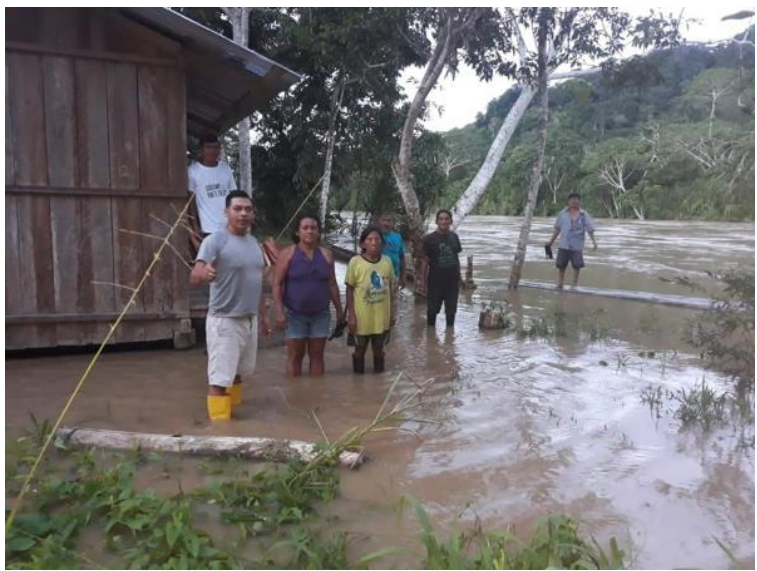

Fuente: Dayuma Nango, presidenta de la Comunidad de Toñampare

representa una sentencia de muerte para estas poblaciones.

http://www.paho.org/spanish/dd/ped/preparativosresp uestalocal.htm.

27 Verónica Grefa. Presidenta de la comunidad Toyuka, Orellana. Comparecencia en la audiencia, 26 de mayo 2020 . 
Una lideresa kichwa ofrece su testimonio sobre las inundaciones y las gestiones que ha realizado para apoyar a las comunidades ante la emergencia.

"Ha estado muy lluvioso [...]. Las chakras fueron arrasadas, la gente ya no tiene sembríos. Están buscando y juntando lo que arrasó, preparando chicha para consumo diario. Están recogiendo la gente plátano que quedó. Han vuelto a sembrar chakras. Más he pedido apoyo con amistades con ONG que nos han hechado la mano, porque del Estado en realidad no hay mayor apoyo. Necesitamos combustible para las motosierras que se usa para desmontar, para hacer. Eso se gestionó. GAD, municipios, juntas parroquiales no han tenido mucho interés por apoyar, dicen que no tienen fondo y ponen excusas". ${ }^{28}$

Ante las inundaciones, la gestión de riesgos por parte del Estado ha sido nula; al igual que para la dotación de kits alimentarios e insumos médicos. Con las inundaciones proliferaron vectores que transmiten enfermedades como el dengue y la malaria, complicándose más la situación de salud de las familias.

Tanto el derrame de crudo, como las inundaciones, fragilizan a las poblaciones en un contexto crítica como el de la pandemia. Esto ocurre mientras se amplía la frontera extractiva petrolera, minera y forestal.

\footnotetext{
28 Entrevista a Rosa Aranda. Presidenta de la comunidad Pihuiri y de la Asociación Sumak Kawsai. Territorio de Moretecpcha, Pastaza.
}

\section{Accionando derechos. El tortuoso camino del acceso a la justicia.}

El 27 de marzo 2020, la Confederación de Nacionalidades Indígenas del Ecuador (CONAIE), la CONFENIAE, la Federación de la Nacionalidad Awá del Ecuador (FNAE), la Alianza por los Derechos Humanos y varias ONG, suscribieron una Acción de Protección orientada a demandar del gobierno nacional las garantías de atención en salud urgentes, idóneas y culturalmente pertinentes frente a la emergencia sanitaria y el cumplimiento de los derechos a la vida, integridad, acceso a la salud y autodeterminación de los pueblos y nacionalidades indígenas.

Se propuso se establezca una mesa técnica que incluya la participación de profesionales especializados en salud $\mathrm{y}$ seguridad y que cuente con asesoría permanente de organizaciones indígenas para proporcionar salud integral a comunidades, y que coordine con los sistemas de autoridad de las comunidades. Demandan acciones culturalmente apropiadas de prevención, dotación de infraestructura e insumos a las unidades de salud, que prestan asistencia a las 
poblaciones indígenas. Así mismo, la implementación y reparación de sistemas de agua segura en las comunidades ${ }^{29}$.

\section{Fotografía 5. Demanda de Acción de Protección frente a la inoperatividad del Estado}

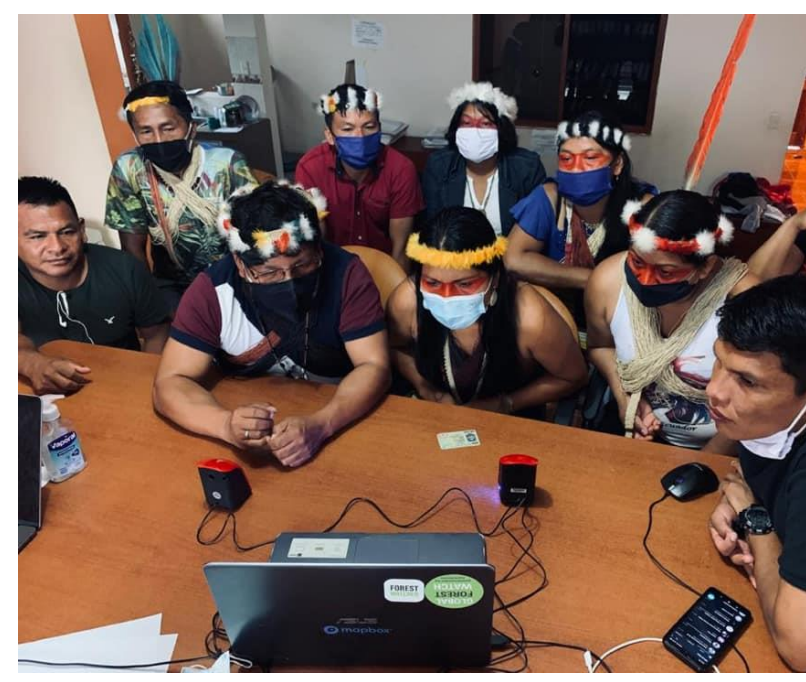

Fuente: CONCONAWEP

Con respecto al derrame de crudo en los ríos Napo y Coca, el 29 de abril de 2020, el Obispo de Aguarico entregó en la Unidad Judicial de Orellana una demanda por Acción de protección y medidas cautelares interpuesta por cerca de 50 demandantes de diversas organizaciones; la mitad provenientes de comunidades. Los accionados fueron los Ministerios de Energía y Recursos No Renovables, el Ministerio de Ambiente, el Ministerio de

29 La comunicación fue remitida dirigida al presidente, la secretaria de Gestión de Riesgos, al ministro de Salud Pública y organismos nacionales e internacionales de Derechos Humanos. Tomado de Amazon Frontlines.
Salud, la Procuraduría General del Estado y las empresas operadoras de los oleoductos Petroecuador EP y OCP. Esta acción recibió apoyo y asesoría legal de la Alianza por los Derechos Humanos, conformada por ONGs e instituciones nacionales e internacionales.

La Acción de Protección se presentó como medida de reparación frente a las acciones y omisiones de los demandados que desencadenaron en la vulneración de una serie de derechos estipulados en la Constitución (2008), tales como el derecho a la vida digna, a la salud, agua, a un medio ambiente sano, alimentación y los derechos de la naturaleza. Por su parte, las medidas cautelares, como un recurso constitucional, buscaba suspender aquellos actos $\mathrm{u}$ omisiones causantes de esas vulneraciones, con la finalidad de precautelar los derechos de las personas afectadas.

El inicio de la audiencia fue diferido en tres ocasiones, hasta que finalmente la primera sesión se instaló vía telemática el 26 de mayo, casi un mes después de presentada la demanda. Durante los 4 días posteriores, más de 40 comuneros mujeres y hombres, se congregaron en uno de los salones del Vicariato de Aguarico en la ciudad de Coca para presentar virtualmente sus testimonios. Distintos miembros de la

https://www.amazonfrontlines.org/chronicles/accionurgente-para-proteger-a-los-pueblos-indigenas-decovid-19-en-ecuador/ 
población afectada expusieron los impactos que el derrame estaba ocasionando en sus vidas y cómo consideraban que sus derechos habían sido vulnerados, en plena pandemia. Para la población kichwa de las comunidades ribereñas del Napo y Coca, ni siquiera la posibilidad de tener acceso a agua para higienizarse era posible, menos aún disponer de agua limpia y segura para su consumo, para el preparado de alimentos y baño.

Los abogados de los demandantes alegaron el desconocimiento de las entidades estatales y las empresas operadoras sobre los parámetros culturales de alimentación, salud, relación con el territorio y los modos de organización comunitaria, así como de parámetros internacionales sobre la provisión de agua en situaciones de emergencia ${ }^{30}$. Se consideraron la flora y fauna afectados, las relaciones ambientales y los significados culturales, recreativos y espirituales que el pueblo kichwa tiene con los ríos; además de contemplarse la naturaleza como sujeto de derechos, conforme la Constitución (2008)

${ }^{30}$ En sus Notas Técnicas sobre Agua, Saneamiento e Higiene (2007), tanto la OPS como la OMS recomiendan la cantidad mínima de 15 litros de agua por persona al día en situaciones de emergencia. Es decir que para una familia de 12 miembros se requieren 180 litros de agua al día. Sin embargo, en el caso del demandante, se le han entregado 24 litros para aproximadamente 3 semanas. OPS/OMS (2007) Preparativos en salud, agua y saneamiento para la respuesta local ante desastres. http://www.paho.org/spanish/dd/ped/preparativosresp uestalocal.htm. reconoce $^{31}$. En contraposición a los planes de remediación ambiental que las empresas operadoras habían emprendido en concatenación con el Ministerio de Ambiente, se solicitó la reparación integral de los ciclos vitales irrumpidos.

Al quinto día, la audiencia fue suspendida debido a que el juez presentó sintomatología asociada a COVID-19. Este evento marca uno de los puntos más álgidos que las comunidades kichwas han tenido que seguir para acceder a la justicia. "Las manchas de petróleo están en el cuerpo de nuestros hijos, por ellos, ijusticia!" rezaba uno de los carteles sostenido por mujeres de las comunidades Kichwa; mientras dos mujeres se encargaban de distribuir mascarillas y botellas de alcohol entre los asistentes.

Compañeros, estamos aquí para exigir justicia. Son 38 días de silencio $y$ no tenemos una respuesta por parte del juez. Vamos a marchar pacíficamente para exigir nuestros derechos. Hemos repartido mascarillas a todos, por favor mantener los dos metros de distancia para que vean que estamos bien organizados. ¡Justicia compañeros!

\footnotetext{
${ }^{31}$ La Constitución Nacional establece en el Artículo 10, inciso segundo, que "La naturaleza será sujeto de aquellos derechos que le reconozca la Constitución". En este sentido, la naturaleza tiene derecho a: 1) respeto integral de su existencia; 2) mantenimiento y regeneración de sus ciclos vitales, estructura, funciones y procesos evolutivos, y 3) derecho a la restauración, como un derecho autónomo al que tienen derecho los individuos y colectivos a ser indemnizados en caso de un daño ambiental.
} 
En los exteriores de la Unidad Judicial representantes de las comunas continuaban coreando consignas alusivas a su pedido de celeridad en el proceso de justicia. Aproximadamente dos horas después la comisión salió del edificio e informó que el juez continuaba enfermo. “¿Acaso solo la salud del juez es importante? ¿Y qué sucede con la salud de los 27.000 indígenas kichwa que hemos sido afectados por el derrame?" decía una lideresa kichwa, mientras caminaban en medio del calor y la humedad.

\section{Fotografía 6. Plantón por demanda de} Reparación ante el derrame, julio 2020

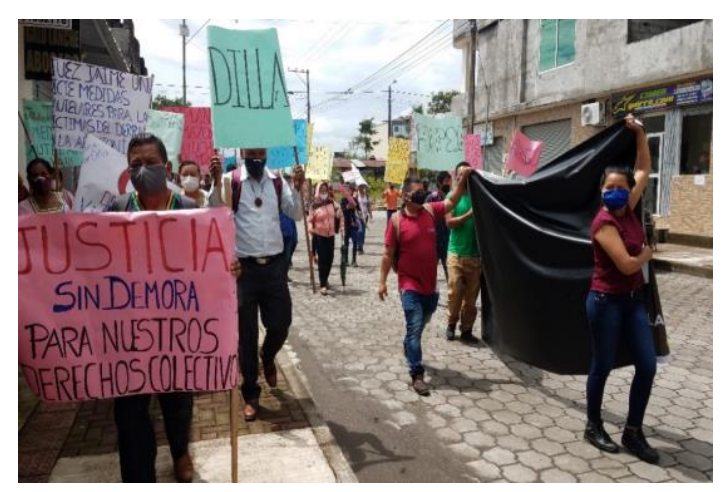

Fuente: Autora

Para el 14 de agosto se programó una nueva marcha, se congregaron alrededor de 120 comuneros y comuneras de las riberas de los ríos Coca y Napo. “iLas manchas de petróleo son para toda la vida! ¡OCP, Petroecuador, no más derrames!" gritaba una lideresa kichwa mientras recorrían las calles de la a ciudad del Coca en dirección a la Gobernación, sin que fueran recibidos.

Finalmente, el 19 de agosto tuvo lugar el último día de audiencia y el juez determinó que el 1 de septiembre daría su veredicto, 147 días después de ocurrido el derrame.

\section{Fotografía 7. Plantón por Reparación Integral y Justicia Ya, agosto 2020}

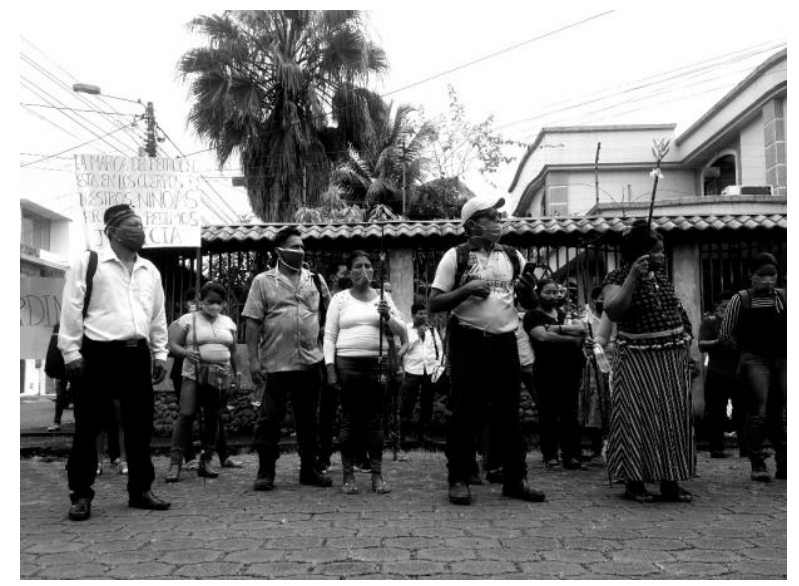

Fuente: Autora

El estado ecuatoriano ha incumplido con el art. 4 lit. 1 del Convenio $\mathrm{N}^{\circ} 169$ que establece que se "deberán adoptar las medidas especiales que se precisen para salvaguardar las personas, las instituciones, los bienes, el trabajo, las culturas y el medio ambiente de los pueblos" indígenas. Al contrario, no solo que no ha realizado acción alguna para salvaguardarlos, sino que en el caso de la contaminación generada por la ruptura de los dos oleoductos (SOTE y OCP) y oleoducto de gasolinas, ha cometido una omisión grave pues la tragedia pudo ser mitigada si se tomaban 
acciones a tiempo. Ha ocasionado graves daños a la salud y aprovisionamiento de alimentos de los pueblos indígenas.

Como se expresa en la dilación del procesamiento de la demanda planteada por la vulneración de derechos de las comunidades y de los derechos de la naturaleza, conforme María Espinoza, abogada que ha acompañado el caso "Hoy una vez más confirmamos lo que los pueblos indígenas vienen confirmando desde hace décadas 'El extractivismo mata', el extractivismo genera discriminaciones brechas y racismo, han pasado 119 días desde el derrame del 7 de abril y se ha condenado de manera impune a que 27.000 personas indígenas estén sin fuentes de agua, sin fuentes de alimento seguras y su salud se vea gravemente expuesta" ${ }^{32}$.

El gobierno atenta contra el art. 13 del Convenio $\mathrm{N}^{\circ} 169$ pues este no ha respetado "la importancia especial que para las culturas y valores espirituales de los pueblos [indígenas] reviste su relación con las tierras o territorios, o con ambos, según los casos, que ocupan o utilizan de alguna

32 EFE, "Indígenas amazónicos impulsan campaña para suspender actividades extractivas" 04/08/2020 EFE https://www.eloriente.com/articulo/como-la-erosionde-la-cascada-san-rafael-tendria-que-ver-con-elrompimiento-del-sote-y-el-ocp/14421

33 Las plantas más recurrentes que mencionan las mujeres kichwa, waorani, shuar, que han utilizado para paliar los síntomas del covid-19 son tabaco Nicotiana tabacum L., chugchuguazo Maytenus macrocarpa chikta, chalwacaspi Goeppertia standleyi, ortiga, otra manera, en particular los aspectos colectivos de esa relación".

\section{El autogobierno de las mujeres desde los saberes curativos.}

\begin{abstract}
La selva es nuestra vida, nuestra farmacia, nuestro mercado y actualmente nos sentimos amenazados porque el gobierno quiere destruirnos para desarrollar a las ciudades más grandes, destruye el aire, el agua, las plantas, la tierra, nuestra vida. Nos cuesta mucho como mujeres resistir y sostener nuestro territorio y sostener el planeta (Nemonte Nenquimo, 12 de agosto 2020).
\end{abstract}

En las comunidades las mujeres recurren a sus conocimientos ancestrales, a la memoria histórica del uso de cortezas, lianas y plantas $^{33}$ para tomas, vaporizaciones y baños. Con estas han logrado bajar la fiebre, disminuir los dolores articulares, y malestares como la dificultad para respirar. En algunos casos, comentan que han combinado plantas medicinales con pastillas y complementos vitamínicos. $^{34}$

chiricaspi Brunfelsia grandiflora, mushuwaska, filaben, wantuk Brugmansia arborea, chulla chaqui, cascarilla, zaragoza, uña de gato y ajo de monte Mansoa alliacea, caspiwasi, cruscaspi, tsuma, guayusa Ilex guayusa, jengibre Zingiber officinale.

34 Patricia Gualina. Diálogos sobre la pandemia. Red Waponi. Menciona el uso de plantas medicinales combinadas con pastillas, complejo b y c,y sueros para reforzar el sistema inmunológico. 
Relatan las mujeres de las distintas nacionalidades, la importancia que ha tenido el uso de plantas medicinales y otras estrategias médicas, así como el apoyarse mutuamente entre mujeres para los cuidados, en medio de la pandemia:

"Mi hijo sí se contagió y yo salí al bosque a recoger plantas medicinales para aplicar a la enfermedad. Como mujeres somos fuertes y aplicamos con papás, hermanas, abuelitos y otras familias más en las comunidades. No sabíamos qué hacer. Yo nunca había experimentado algo así. La gente estaba sin plata y hubo que ir a coger las plantas. ${ }^{35}$

"La medicina que elaboro ha evitado que mi esposo, hijos y yo misma me infecte con el virus. Eso que he estado en contacto con familiares y personas del pueblo que dieron positivo en las pruebas PCR y han acudido donde mí para ser curados. Para prevenir el virus, ahumo la casa y a las personas enfermas con plantas fuertes como verbena y chimbio, con otras preparo una bebida poniendo ajo de monte..." También hay plantas que uso en lugar del alcohol-gel. Hay que ponerse en la cara y las manos para salir, además aspiro tabaco (Nicotiana tabacum) que mantiene protegidas las vías respiratorias". ${ }^{36}$

"Mi mami practica medicina ancestral, entonces utilizamos esto... Las pastillas de paracetamol no ayudaban, solo

35 Entrevista a Zuritiak Naichamp. Comunidad shuar de Warintz, Morona Santiago.

36 Entrevista Zoila Castillo Tuti. Mujeres defensoras de la Selva. Reside entre el Puyo y la comunidad de Teresa Mama.. pasaba unas horas. Utilizaban entonces alcanfor o chuchuhuazo con trago. Todos los días todos se hacían el tratamiento con medicina natural. Decíamos "resistir es mi derecho". Nosotros tenemos parte de la solución, con lo que conocemos y tenemos... la medicina natural. El GAD parroquial de Macuma, mandó a preparar medicina natural" ${ }^{37}$.

En el caso de la nacionalidad wao, las pikenani (ancianas sabias) han creado medicina natural para curarse y son ellas quienes sostienen a los enfermos. Por medio de las vaporizaciones hicieron resistencia al Covid-19; por medio de su sabiduría han ido a la selva (omere) y han tomado ajo de monte, uña de gato, sangre de drago para preparar medicina en base a conocimientos heredados entre generaciones. Una de las plantas más utilizadas es la ortiga (wento), utilizada para disminuir el dolor en el cuerpo, también para quitar la fiebre y los dolores de cabeza.

Para evitar la propagación del virus, las mujeres kichwa desinfectan el interior de sus casas con verbena Verbena officinalis y guandug Brugmansia arborea machacado y las mujeres waorani con ajo de monte Mansoa alliacea. Dentro del proceso curativo se habla de dietar, prescriben el consumo de pescado y prohíben la ingesta de carne. Se

37 Entrevista a Yadira Sharupi, comunidade del Consuelo (Vía Puyo-Macas). Dirigenta de Relaciones Internacionales FENASH 
ortiga a los enfermos para bajar la intensidad de los fuertes dolores de cabeza y se prescriben baños con plantas y bejuco, más ajo de monte para dolores corporales. ${ }^{38}$

\section{Fotografía 8: Wento (ritual de Ortiga)}

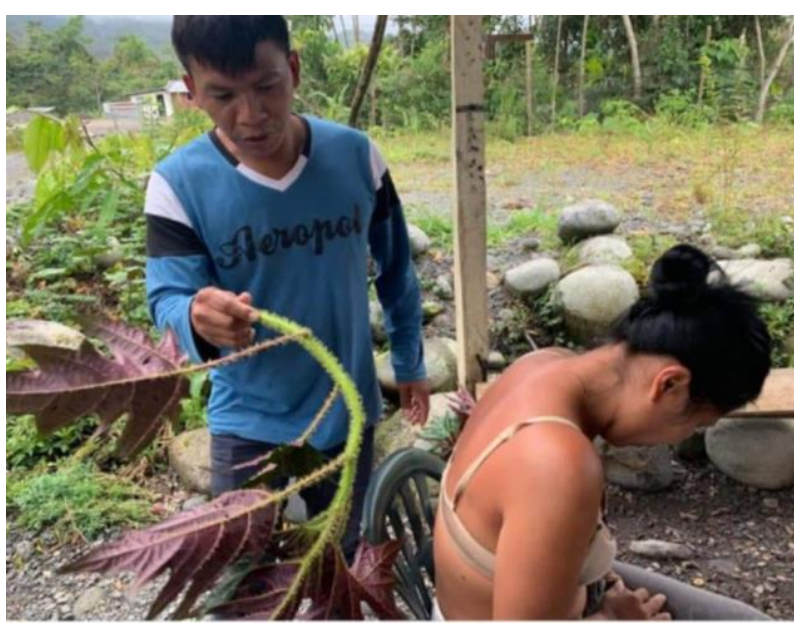

Fuente: CONCONAWEP

No es la primera vez que las mujeres indígenas amazónicas hacen uso de sus conocimientos ancestrales, $\mathrm{su}$ autodeterminación y de lo que les provee la selva para curar enfermedades ligadas a la colonización. Como dice una mujer yachak "la gente de afuera siempre trae la enfermedad"39. Las mujeres afectadas por el derrame se quejan de no poder acceder a las plantas curativas, lo que les vuelve más vulnerables.

38 Nemonte Nenkimo. Presidenta de CONCONAWEP. Diálogos sobre la pandemia. Red Waponi.

39 Entrevista a Ana Gualinga, agosto 2020. Pastaza

40 Kawsak Sacha "está constituida por todos los seres de la Selva, desde los más infinitesimales hasta los seres más grandes de los mundos, animal, vegetal, mineral, espiritual y cósmico, en intercomunicación con los
Varias mujeres amazónicas en ciudades relatan haber ayudado $\mathrm{y}$ hospedado a familiares diagnosticados con Covid-19, aún a riesgo de contagiarse, y también han mostrado sororidad para con mujeres mestizas que les han pedido ayuda. Se revela en esto, la importancia del minkanakuy: "cuidado de unos por otros que incluye a todos los seres vivos con diferentes estados ontológicos" (Rodríguez, 2020). La red de cuidados es extensiva a todos los seres que habitan en su territorio, incluyendo lo que Occidente denomina "naturaleza", que para el pueblo kichwa es Kawsak Sacha (Selva Viviente) ${ }^{40}$ y para otros pueblos amazónicos está incluido en el campo cultural donde se encuentran ordenados animales, plantas y espíritus (Descola, 1998; Latour, 2007).

\section{Mujeres y hombres indígenas} establecen profundas relaciones con el entorno para restaurar la salud. Los tratamientos que realizan las mujeres sabias (yachakuna), se asientan en la memoria histórica y para la puesta en práctica consultan con las y los mayores. ${ }^{41}$ Las mujeres waorani plantean que acuden a sus conocimientos como sus ancestros, y a las plantas que se encuentra en su selva (Ome).

seres humanos brindándoles lo necesario para revitalizar sus facetas psicológicas, físicas, espirituales, restableciendo así la energía" (Pueblo Originario Kichwa de Sarayaku 2018).

41 Referencias de Entrevista a Ana Gualianga. Te Zulay, Pastaza. 
No solo los abuelos y abuelas enseñan, también hay seres portadores de conocimientos que en las tomas de Guantuk Brugmansia arborea o de Ayawaska Banisteriopsis caapi. enseñan a los humanos qué parte de las plantas utilizar, cómo preparar y curar. Todo ello lleva a resaltar la importancia de salvaguardar su territorio y las relacionalidades que en estos se establecen.

La mayoría de mujeres indígenas han descartado ir al hospital, pues "se escucha en los hospitales que la gente se muere, no hay camas, no les atienden, entonces la gente indígena tiene mucho miedo $[\ldots]$, por esas razones se tratan con los yachak, y con la medicina ancestral de

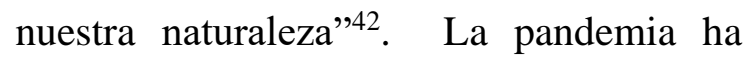
dejado lecciones en las comunidades, y para algunas lideresas amazónicas, el ver que sus saberes curativos, las plantas de la selva pueden ser efectivas ha reforzado su interés por precautelar sus territorios. Así los expresa Yadira Sharupi: "En este caso del covid 19 tuvimos que sacar de nuestras raíces, de nuestra cosmovisión espiritual para curarnos con nuestra propia medicina. De allí la importancia de proteger y defender nuestro territorio de las petroleras, de la contaminación de los ríos. ${ }^{43}$

42 Entrevista Nancy Santi Kuraka del Pueblo Kichwa de Kawsak Sacha. Comunidad de Sisa. Mini-serie covid19.

43 Entrevista a Yadira Sharupi. Vice síndica de la comunidade del Consuelo, km 65, vía Puyo-Macas.
Con lo descrito, se observa que las mujeres indígenas amazónicas han asumido el control de la salud de sus pueblos para preservar la vida en sus comunidades, a través de la aplicación de sus conocimientos ancestrales para tratar el Covid-19 y evitar el contagio. Esta situación ha sido la respuesta de los pueblos indígenas frente a la indiferencia del Estado. Se podría decir que, en la práctica, ponen en ejercicio lo que el Convenio $N^{\circ} 169$ de la OIT les reconoce, el derecho como pueblos indígenas a "asumir el control de sus propias instituciones y formas de vida".

\section{Conclusiones}

La pandemia del coronavirus ha golpeado fuertemente a los pueblos amazónicos, como lo describen mujeres indígenas, al extenderse los contagios conforme la circulación en territorios comunitarios, de actores externos ligados a actividades extractivas del petróleo, minería y extracción forestal. También como se detalla en el artículo, en simultáneo a los meses de padecimiento de la pandemia, ha habido comunidades afectadas por inundaciones y contaminación por derrame de petróleo en importantes ríos amazónicos,

Dirigente de Relaciones Internacionales de la Federación de la Nacionalidad Shuar de Pastaza (FENASH). 
limitándose su acceso al agua y alimentos vulnerando aún más sus cuerpos.

El accionar del Estado ecuatoriano ha sido nulo. En la Amazonía se niega acceso a servicios de salud, a una detección temprana, al monitoreo y atención oportunas de la pandemia. A la vez, el sistema de justicia no ha tenido celeridad para procesar demandas de exigibilidad de derechos (de salud, reparación integral, entre otros). El dejar morir hace parte, como se ha presentado en este artículo, de la estrategia de desechabilidad que se fragua en la Amazonía con respecto a los pueblos indígenas y que se manifiesta en la necropolítica existente.

Las mujeres indígenas en este contexto desde las bases de sus comunidades y activas en los procesos organizativos de sus pueblos, defienden la continuidad de la vida y la sostienen. Así como se movilizan para exigir justicia, revitalizan conocimientos y ensayan saberes curativos relacionadas con plantas medicinales, e intentan contener un virus no conocido y exógeno. En su memoria están las experiencias transmitidas de epidemias previas, de la letalidad de las mismas, pero también su persistencia. En las comunidades, e incluso en aquellas mujeres de familias amazónicas trasladadas a espacios urbanos, se ha acentuado la convicción de que defender y precautelar sus territorios les posibilita asegurar su subsistencia y encontrar alternativas a la muerte.

Consideran las mujeres que es importante redoblar esfuerzos para fortalecer las luchas territoriales, detener la contaminación sobre ríos y bosques, armonizar las relaciones con el entorno, retornar a sus prácticas y saberes curativos propios del Kawsak Sacha (Selva Viviente) para sostener la vida; si bien entienden que se necesita un reparto más equitativo en la gestión de los cuidados.

\section{Referências}

ALENCAR, Ane et al. Amazônia em chamas $O$ fogo e o desmatamento. IPAM, abril 2020. N.-3.

ARBELÁEZ CAMPANILLA, Diego, ANDREYEVNA, Marianna y ROJAS, Magda. "Las pandemias como factor perturbador del orden geopolítico en el mundo globalizado". Cuestiones Políticas Vol 36 (63): 134-150. 2019.

CABODEVILLA, Miguel Ángel. Los huaorani en la historia de los pueblos del oriente. Quito: CICAME. 2013

CHAMBOULEYRON, Rafael; COSTA BARBOSA, Benedito; BOMBARDI, Fernanda Aires; ROCHA DE SOUSA Claudia. "Formidable contagion: epidemics, work and recruitment in Colonial Amazonia 1660-1750". História, Ciências, Saúde - Manguinhos, Rio de Janeiro 2011

DE CASTRO, Fabio; RUSSO LOPES, Gabriela, SONNEWEND BRONDIZIO, Eduardo. The Brazilian Amazon in Times 
of COVID-19: from crisis to transformation?" Revista Ambiente \& Sociedade. 2020

DE SOUZA SANTOS, Debora." Disproportionate impact of COVID-19 among pregnant and postpartum Black Women in Brazil through structural racism lens". Editorial. Published by Oxford University Press for the Infectious Diseases Society of America. 2020.

CONDE, Maité. "Brazil in the time of Coronavirus. Geopolítica(s)". Revista de estudios sobre espacio y poder. Vol 11:239-249. 2020

CONFENIAE, Registros de Monitoreo del Covid-19 en la Amazonía ecuatoriana. 2008-2020

DESCOLA, Philippe. La Selva Culta. Simbolismo y praxis en la ecología de los Achuar, Quito: IFEA, Ediciones AbyaYala. 1987

" Descola Philippe y los Achuar: La naturaleza no existe" Entrevista de Gerar Coffey. Revista La línea de Fuego, mayo 16, 2018, acceso el 24 de mayo de 2018.

ESTEVEZ, Adriana. "Biopolítica y necropolítica: ¿constitutivos u opuestos?” Espiral, Estudios sobre Estado y Sociedad Vol.XXV. No. 7 Septiembre / Diciembre de 2018.

FELLOWS, Marta, et all. They Are not Numbers. They Are Lives! COVID-19 threatens indigenous peoples in the Brazilian Amazon. Brasilia: COIAB, IPAM. 2020

FOUCAULT, Michel. Nacimiento de la biopolítica. Buenos Aires: edición en español por el Fondo de Cultura Económico. 2007

GARCIA, Marc et al.. "The Color of COVID-19: Structural Racism and the
Pandemic's Disproportionate Impact on Older Racial and Ethnic Minorities". Published by Oxford University Press on behalf of The Gerontological Society of America. 2020

GEE, Gilbert y CHANDRA, Ford. "Structural racism and health inequities". Du Bois Rev. No. 8: 115-132. 2011

GÓMEZ, Augusto. "Etnocidio. Una reseña de los procesos de destrucción sociocultural de las sociedades indígenas en la Amazonía Colombiana. Ponencia presentada en el Simposio de médicos, medicina y violencia. Ministerio de Defensa Nacional, Universidad Militar Nueva Granada, Facultad de Medicina. Sociedad Colombiana de Historia de la Medicina. Septiembre 22. 1995.

GÓMEZ, Javier. “Amazonía Colombiana. Contacto, contagio y catástrofe demográfica indígena". Magazine 13: 143163. 1998.

GONZALES CASTILLO Jorge. et al. Pandemia de la COVID-19 y las Políticas de Salud Pública en el Perú. Rev. Salud Pública. 22(2): 1-9. 2020.

GOLDÁRAZ, José Miguel. Samay, la herencia del Espíritu. Cosmovisión y ética Naporunas. Quito: CICAME. 2005 Mushuk Pacha. Hacia. La Tierra sin mal. Quito: CICAME. 2004

Global Preparedness Monitoring Board (GPMB). 2019. A word at risk. Annual report on global preparedness for health emergencies. Geneva: WHO.

Grzinic M y Táthic S. 2014. Necropolitics, racialization and global capitalism Historization of Biopolitics and forensic of politics, art and life. Lanham: Lexington Books.

IGLESIAS-OSORES Sebastian, SAAVEDRA-CAMACHO Johnny 
Leandro. "COVID-19 en comunidades indígenas del Perú: casos y accesibilidad a servicios de salud". An Fac

med.;81(2):250-1. 2020.

KOHN, Eduardo. "Toward an ethical practice in the Anthropocene". Hau: Journal of Ethnographic Theory 4 (1): 459-464. 2014.

Latour, Bruno. Nunca fuimos modernos. Ensayo de antropología simétrica. Buenos Aires:.Siglo XXI editores, 2007.

“¿Qué medidas de protección para evitar el regreso del modelo de producción de la precrisis?. 2020

LÓPEZ-FELDMAN, et al. "Environmental Impacts and Policy Responses to Covid19: A View from Latin America".

Environmental and Resource Economics. 2020

LOVELL, George y COOK David. Juicios secretos de Dios. Epidemias y despoblación indígena en Hispanoamérica colonial. Quito: Abya Yala. 1999

MALHEIRO, Bruno Cezar; MICHELOTTI Fernando; GUEDES SABINO, Thiago. Aqui o capitalismo não parou! Espoliação e brutalidade em tempos de pandemia, o que a Amazônia tem a dizer? Niterói, Universidade Federal Fluminense GEOgraphia, vol: 22, n. 48, 2020.

MENESES-NAVARRO, Sergio., FREYERMUTH-ENCISO, María.Gabriela., PELCASTREVILLAFUERTE, Blanca.Estela. et al. The challenges facing indigenous communities in Latin America as they confront the COVID-19 pandemic. International Journal for Equity in Health, 19: 63. 2020.

MENEZES Emily Rosário, OLIVEIRA DA FONSECA Laimara, DE OLIVEIRA FERREIRA Riscos. Vulnerabilidades e proteção no enfrentamento da Covid-19 no
Amazonas: notas reflexivas. Revista Arquivos Científicos (IMMES). Macapá, AP, Ano, v. 3, n. 2, p. XX-XX. 2020.

MBEMBE, Achile. La necropolítica. Seguido de sobre el gobierno privado indirecto. España. Melusina. 1999.

MONASTERIO Martín Marta y WEINGÄRTNER Julia. 2010. Poner la vida en el centro, Ecologistas en Acción de Madrid. 2010

MUYOLEMA, Armando. "The poetics of Sumak Kawsay on a global Horizon", En $A$ Postcapitalist paradigm: The common good of humanity, 293-307. Francois Houtart, Birit Daiber (ed.), Brussels: Rosa -Luxemburg-Foundation Brussels. (Traducción propia). 2012

NEIRA, Hernán; RUSSO, Lorena Inés; ÁLVAREZ SUBIABR,

Bernardita. Reviste de filosofía. vol.76. Santiago de Chile. diciembre. 2019

Powell John. Structural racism. Building upon the insights of John Calmore. Law Review No 86: 791-816.2008

Pueblo Originario Kichwa de Sarayaku. "Declaratoria Kawsak Sacha Selva Viviente, ser vivo y consciente sujeto de derechos" Puyo. 2018.

PULIDO Laura. Geographies of race and ethnicity II: Environmental racism, racial capitalism and state-sanctioned violence. Sage. 2016.

RODRÍGUEZ PÉREZ, Marisol. La comunidad indígena ¿ejercicio o utopía? Revitalización comunitaria y defensa territorial, adaptaciones a las nuevas dinámicas del capitalismo: el caso de la comunidad de Cumbijín (Cotopaxi). Tesis de maestría, FLACSO-Ecuador. 2016.

"El Minkanakuy como eje de valores kichwas y su influencia en el entorno", Ponencia presentada en las 
Jornadas de Etnobiología para tod@s, Sociedad Ecuatoriana de Etnobiología y Sociedad Latinoamericana de Etnobiología, Quito. 2020

SANTOS GRANERO, Fernando.

Epidemias y sublevaciones en el desarrollo demográfico de las misiones Amuesha del Cerro de la Sall, Siglo XVIII. HISTORICA. Vol. XI. NO 1. Julio de 1987.

SOJO, Ana. "Encrucijadas de la salud pública latinoamericana en un mundo global. Pandemia y/o pandemónium". Documentos de Trabajo.37. Fundación Carolina. 2020.

SVAMPA, M., \& VIALE., E.. Maldesarrollo: La Argentina del extractivismo y el despojo. Buenos Aires, Argentina: Katz Ediciones. 2014

TIFFANY, John. "Intersection of Bias, structural racism and social determinants with health inequities. Pediatrics Vol 146 (2). 2020

ULLOA, Astrid. Dinámicas ambientales y extractivas en el siglo XXI: ¿Es la época del antropoceno o del capitaloceno en América Latina? Desacatos. Mayoagosto.2017. No. 54. pp. 58-73. 2017.

VALLEJO Ivette, ÁLVAREZ Kati. La pandemia del Coronavirus en la Amazonía ecuatoriana: vulnerabilidades y olvido del Estado. Cadernos de Campo (São Paulo, online). vol. 29, n.1. USP 2020. P p.95110. 2020

VERDUM, Ricardo. As obras de infraestrutura do PAC e os povos indígenas na Amazônia Brasileira. Brasilia: INESC. 2012

VILLAVICENCIO, Paola. La pandemia de Covid-19 y la crisis climática: Dos emergencias convergentes. Revista Catalana de Dret Ambiental. Vol. XI Núm. 2: $1-27.2020$.
VIVEIROS DE CASTRO, Eduardo. Metafísicas caníbales. Líneas de Antropología postestructural". Madrid: Katz Editores.2010

ZINZI Lancet et al. Structural racism and health inequalities in the USA: evidence and interventions. vol 389: 8-14. 2017.

CONFENIAE. Actualización de registros COVID-19 2020.

https://confeniae.net/2020/actualizacionde-registros-de-covid-19-y-lanzamientodel-portal-interactvio-para-monitoreo-delimpacto-de-la-pandemia-en-territoriosamazonicos .

HERRERO, Yayo. Miradas ecofeministas para revertir la guerra contra la vida.

Conferencia audiovisual. En: https://www.youtube.com/watch?v=Zg2eE s5sIhI. Visto el 3 de Julio 2018

MORÀN, Juan. "Desastres paisajísticos, ambientales y sociales en Ecuador:

La caída de la Cascada de San Rafael, la erosión remontante y el derrame que le siguió" 2020.

http://agenciaecologista.info/2020/07/13/ca scada-san-rafael/

REPAM-COICA. 2020. Boletín del impacto del COVID-19 en los Pueblos Indígenas de la Panamazonía. https://redamazonica.org/2020/05/boletindel-impacto-del-covid-19-en-los-pueblosindigenas-de-la-panamazonia/ 